\title{
The Use of Genetic Algorithm and Annealing Algorithm for The Optimization of Dimension Chain
}

\author{
Haiming Kan ,Haibin Li \\ Ministry of Education Key Lab of Contemporary \\ Design \& Integrated Manu. Tech. \\ Northwestern Polytechnical Uni \\ Xi'an , China
}

\begin{abstract}
The error accumulation is currently working procedure dimension chain, an important problem in the increasing of the error will reduce production speed and increase production cost. Traditional mode of production in production efficiency and production cost above tend to attend. This paper using Simulated Annealing (SA) algorithm and genetic algorithm (GA) combination of mixed Simulated annealing and Genetic algorithm (SG algorithm), put genetic algorithm's parallelism into annealing algorithm, thus improving annealing algorithm in computational speed. In a certain extent to optimize dimension chain, reduce error accumulation calculation speed, reduce production cost.
\end{abstract}

Keywords-dimension chain, SG algorithm, parallelism, optimize

\section{INTRODUCTION}

Currently the tolerance and accumulated of dimension chainstep are going for steps, for that design cycle is long, increase the cost of production, also go against CAD/CAM integration and development of concurrent engineering. Meanwhile, in CAPP it hasn't the evaluation method to compare the disadvantages of the process route technical and economic indexes. Therefore, in the design phase to fully consider processing method, comprehensive factors such as cost, quality is established on the basis of the mathematical model.SG algorithm main introduced GA's parallelism to simulated annealing to improve the computational speed of SA.[1] Therefore, good stability will GA and to improve the algorithm for SA mixed is a good choice.This passage put some of the advantages of genetic algorithm into annealing algorithm, in its basis, the optimized calculation procedure sizes chain, in order to reduce the error accumulation of computational speed. This to promote the concurrent engineering implementation, reduce production cost to have the important meaning.[2]

\section{ALGORITHM OVERVIEW}

Simulated annealing algorithm compared combinatorial optimization problem to statistical mechanics, the thermal equilibrium problems based on monte carlo analogy iteration method is based on physics, the solid material the annealing process a heuristic random search algorithm. When nearing the most advantage its to the direction of the objective function of the mobile increases the probability of zero, thus

\author{
Jie Liu, Weilong Zhang \\ Ministry of Education Key Lab of Contemporary \\ Design \& Integrated Manu. Tech. \\ Northwestern Polytechnical Uni \\ Xi'an , China
}

make the final current solution of optimal solution for the system.[3]

The advantage of simulated annealing algorithm is very few restrictions on function, versatility, doesn't require meet convergence criteria, can be continuous, can also discrete, the optimal solution isn't dependent on the initial value, so, and algorithm easily theoretically if the length of markov chains, can guarantee for unlimited converge to the global optimal.But the computation is very big,and wastes a lot of time. The two most significant characteristics of genetic algorithm is implied parallelism and global search space. This in some extent could compensate for the shortcomings of annealing algorithm, so can consider the genetic algorithm is parallelism and global searching capability into annealing algorithm, thus improve annealing algorithm.[4]

Annealing genetic algorithm combined the simulated annealing algorithm and the genetic algorithm, the simulated annealing algorithm based on genetic algorithm, the group by introducing the concept of operation and the genetic algorithm into genetic algorithm, a hybrid algorithm thoughts constitute. It doesn't like simulating genetic algorithm such only by a single point iterative method, but through selecting and constantly improve the variable quality, and eventually group get optimal solution. Its basic steps briefly described as follows:

1: randomly generated contains $\mathrm{m}$ an initial group $\mathrm{P}=0$, and make $\mathrm{k}=0$.

2: determine the initial temperature t0, crossover operator $\mathrm{PC}$ and $\mathrm{Pm}$.

3: to the group $\mathrm{P}(\mathrm{k})$ each individual temperature tk under markov chain length $\mathrm{L}$, and according to accept or abandon evolvement Metropolis standards; After cooling, get the new group $\mathrm{P}^{\prime}(\mathrm{k})$.

4: from the group $\mathrm{P}^{\prime}(\mathrm{k})$ produced by randomized to individual group pairing of $\mathrm{m}$. each pair of individual press given crossover operator and mutation operator crossing and variation operation implementation respectively, and get a new individual for the group of $2 \mathrm{~m}$. Form groups $\mathrm{P}^{\prime}(\mathrm{k}+1)$.

5: From $\mathrm{P}^{\prime}(\mathrm{k}+1)$. select the $\mathrm{m}$ an individual component progeny population $\mathrm{P}(\mathrm{k}+1)$. under Metropolis criteria.

6 Conditional judgment, if not satisfy the conditions for the termination attenuation function, then the temperature, the temperature parameters $\mathrm{tk}+\mathrm{l}=\mathrm{d}(\mathrm{tk}), \mathrm{k}=\mathrm{k}+1$ to update the third step; If meet the conditions for the termination, the output current optimal solution, algorithm ended.[5] 


\section{Dimension Chain Optimization Model}

A set of interrelated and order according to certain combinations of the closed size called dimension chain. On behalf of dimension chain basic relationships are used to explain the basic principle and dimension chain nature of the problem, In establishing the basic relations between dimension chain has the extremely vital significance. To illustrate the internal factors, half the available figure 1 dimensional chain to explain.[6]

Assembly size chain cost is composed by all dimensions have more ring the processes of processing cost, processing method is different, the mutual influence procedure sizes error is different also, namely each size of comprehensive and accumulated between error is different also. Consider each procedure must be optimizing processing method, the total cost for $\mathrm{CS}$ :

$$
\min C_{S}=\sum_{i=1}^{n} \sum_{j=1}^{Q_{i}} \sum_{k=1}^{P_{i j}} \mu_{i k} C_{i k}\left(T_{i k}\right)
$$

In this formula:n - Assembly in dimension chain component loop size total; $\mathrm{Q}$ - a component loop processes of number $\mathrm{i} ; \mathrm{Pij}$ - The first $\mathrm{i}$ a component loop size $\mathrm{j}$ procedure can choose the number of processing methods;

$\mu_{i k}$ _ Processing methods choose coefficient, First i A component loop size first $\mathrm{j}$ procedure of processing method choice when the $\mathrm{k}, \mu_{i k}=1_{\text {or }} \mu_{i k}=0_{;}$Cik(Tik) -First i A component loop size first $\mathrm{j}$ procedure of processing method choice when first $\mathrm{k}$ the cost - tolerance function.

This model has the following three constraints

(1). Each procedure, alternative economic processing precision scope, component loop size precision machining accuracy range of economic constraints formula is:

$$
T_{i j k}{ }^{-}<T_{i j k}<T_{i j k}{ }^{+}
$$

In this formula: $T_{i j k}{ }^{-}, T_{i j k}{ }^{+}$-First i A component loop size first $\mathrm{j}$ procedure in the choice of when the first $\mathrm{k}$ processing method and procedure sizes tolerances of boundary.

(2). Machining allowance tolerance constraint Machining allowance tolerance is to point to in machining process on from processed surface, because the thickness resection procedure sizes exist tolerance, so also existing machining allowance of tolerance Its constraint for the first $\mathrm{i} A$ component loop before the second word size adjacent sum process tolerance will be less than or equal to the machining allowance after procedure of tolerance Its constraint for the first A A component loop before the second word size adjacent sum process tolerance will be less than or equal to the machining allowance after procedure of tolerance B:

$$
T_{i j}+T_{i(j-1)} \leq T_{z i j}
$$

So first i a component loop optimal size each working procedure when machining allowance processing method for tolerance constraints:

$$
\sum_{k=1}^{P_{i j}} \mu_{i j k} T_{i j k}+\sum_{k=a}^{P_{i(j-1) k}} \mu_{i(j-a) k} T_{i(j-1) k} \leq T_{z i j}
$$

Processing methods selection constraint:

$$
\sum_{k=1}^{P_{y}} \mu_{i k} \equiv 1 \quad \mathrm{i}=1,2, \cdots, \mathrm{n} ; \mathrm{j}=1,2, \cdots, 0_{\mathrm{i}}
$$

On each working procedure of ensure corresponding processing method to select a only.

(3). Assembly size chain functional requirement constraint. Using extremum method boundary. First i a component loop size tolerance on the final machining process after processing methods for selection:

$$
T_{i}=\sum_{k=1}^{P_{i j}} \mu_{i 0_{i} k} T_{i 0_{i} k}
$$

In this formula: ${ }^{0}-$ First $i$ a component loop size end processing operations Numbers. Extremum boundary:

$$
\sum_{i=1}^{n} \sum_{k=1}^{P_{i 0_{0}}} \mu_{i 0_{i} k} T_{i 0_{i} k} \leq T_{\sum}
$$

In this formula: $\mathrm{T}$-Assembly size chain closed loop design tolerances; $P_{i 0_{i} k}$ - First i a component loop size selection processes at the processing method number; $T_{i 0_{i} k}$ First i a component loop size end processing operations first $\mathrm{k}$ when processing method of tolerance; $\mu_{i 0_{i} k}$-First i a component loop size final machining operations processes of choice coefficient.

Because in the design of the optimization model, design variables include continuous variables and discrete variables, so this is a complex optimizing model. The disturbances in annealing is divided into two overlapping part: choose coefficient perturbation algorithm and tolerance disturbance algorithm, Its program as shown in Figure 1

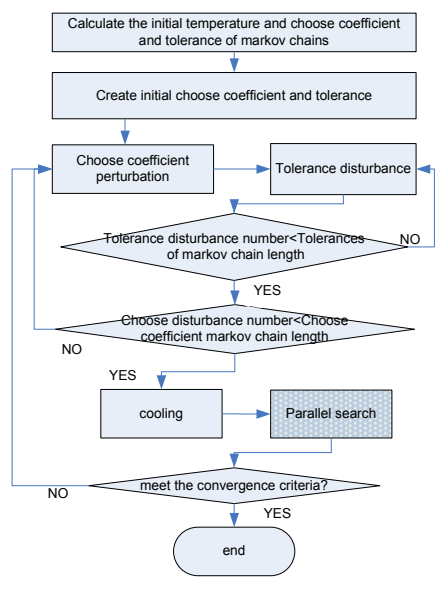

Figure 1. Algorithm flowchart

\section{APPLICATION EXAMPLES}

As shown in figure 2 shows, An internal-combustion engine for $\Phi 80 \mathrm{~mm}$ diameter of the cylinder, And the piston formation with holes, shaft (Parts material for steel, aluminium alloy respectively). Accuracy requirement to cater for the clearance $X_{\Sigma}=0.056 \pm 0.025 \mathrm{~mm}$ Hole shaft dimension independent and for normal distribution, Parallel to the optimized design with tolerances.

The hole, shaft with component loop $n=2$, Including subscript $\mathrm{i}=1$ representative holes, $i=2$ represents shaft dimension; 1,2 component loop size process 
number01 $=01=4,1,2$ component loop size selection of processing method number $\mathrm{Pij}$ is $\mathrm{P} 12=\mathrm{P} 13=\mathrm{P} 14=\mathrm{P} 21=\mathrm{P} 22=\mathrm{P} 23=\mathrm{P} 24=2$ Assembly size chain accuracy requirement of boundary method using extremum constraints, then use the simulated annealing algorithm was used to optimize the design, See the table below the tolerance allocation, From the table with that of outer diameter of piston cylinder respectively every process selection as follows: tolerance Tijk:

$\mathrm{T} 111=0.864 \mathrm{~mm}, \mathrm{~T} 122=0.193 \mathrm{~mm}, \mathrm{~T} 131=0.066 \mathrm{~mm}, \mathrm{~T} 141=$ $0.028 \mathrm{~mm}, \mathrm{~T} 211=0.813 \mathrm{~mm}, \mathrm{~T} 222=0.183 \mathrm{~mm}, \mathrm{~T} 231=0.066 \mathrm{~mm}$, $\mathrm{T} 242=0.019 \mathrm{~mm}$;

Through calculation, the optimum process for total cost: $C_{s \min }=147.27$. So selected cylinder and piston with holes, shaft for: $\Phi 80(\mathrm{H} 7 / \mathrm{H} 6)$

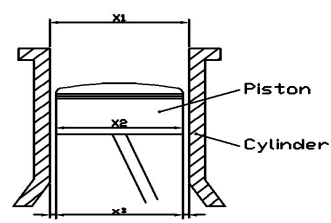

Figure 2. Hole and shaft mating matrix drawing

\section{SUMMARIES}

GA to parameter set is its operation, the coding form rather than code itself; Search for group, rather than a single point, it reflects the parallelism; Don't need other auxiliary knowledge to guide search, algorithm. In this passage, the genetic algorithm is parallelism into annealing algorithm, considering the calculation speed and cost requirements, reduce the production period, be helpful for the development of concurrent engineering. And the example also proved the method is more sciencific and accurately than traditional methods.

\section{REFERENCES}

[1] Fang hong-fang. Computer Aided Prpcess Dimensioning And Tolerancing, China textile university press,2000,pp95-98

[2] Jiang zhuang-de. Mechanical Precision Design. Xi'an traffic university press. 2000.6.

[3] Fang hong-fang, WU zhao-tong. Simulated annealing algorithm in the application of computer aided the tolerance design, The Chinese automation academic conference proceedings, 1995

[4] Kirpatrick S,et al.optimization by simulated annealing,science, 1983,22,pp671-680

[5] Pan xiao-quan, Landing gear cutting parameters optimization research by Genetic annealing method, Northwestern Polytechnical University Master thesis, 2007

[6] Wang xiao-hui, Dimension design principle and application, National defence industry press, 2004

TABLE I. SG ALGORITHM TO OPTIMIZE THE RESULTS

\begin{tabular}{|c|c|c|c|c|c|c|c|}
\hline & & & Tijk & m) & & & \\
\hline & $\begin{array}{l}\text { operations } \\
\text { opd }\end{array}$ & & Machinin & tethods $K$ & & & \\
\hline & & 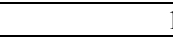 & & & 2 & 1 & 2 \\
\hline 1 & 1 & Rough boring & $0.864(\mathrm{IT} 14)$ & $\begin{array}{c}\text { Fine } \\
\text { expansion }\end{array}$ & 0.054(IT13) & 1 & 2 \\
\hline $\begin{array}{l}\text { (Cyl } \\
\text { inde }\end{array}$ & 2 & $\begin{array}{c}\text { Fine } \\
\text { expansion }\end{array}$ & $\begin{array}{c}0.24(\mathrm{IT} 11- \\
12)\end{array}$ & $\begin{array}{c}\text { Semi-fine } \\
\text { boring }\end{array}$ & 0.193(IT11) & 1 & 0 \\
\hline & 3 & Fine boring & $\begin{array}{c}\text { 0.066(IT8- } \\
9 \text { ) }\end{array}$ & Grinding & 0.046 (IT8) & 1 & 0 \\
\hline & 4 & $\begin{array}{c}\text { Diamond } \\
\text { Boring }\end{array}$ & 0.028 (IT7) & Grind & 0.019 (IT6) & 1 & 0 \\
\hline & Tolerance & & & $028 \mathrm{~mm}(\mathrm{H} 7)$ & & & \\
\hline & & & Tijk & m) & & & \\
\hline & $\begin{array}{l}\text { Macnining } \\
\text { operations }\end{array}$ & & Machinin & tethods $K$ & & & \\
\hline & & 1 & & & 2 & 1 & 2 \\
\hline & 1 & $\begin{array}{c}\text { Rough turning } \\
\text { (1) }\end{array}$ & $0.813(\mathrm{IT} 14)$ & $\begin{array}{c}\text { Rough } \\
\text { turning (1) }\end{array}$ & 0.60 (IT13-14) & 1 & 0 \\
\hline $\begin{array}{c}2 \\
\text { (Pist }\end{array}$ & 2 & $\begin{array}{l}\text { Semi-fine } \\
\text { turning(1) }\end{array}$ & $\begin{array}{c}0.220(\mathrm{IT} 11- \\
12)\end{array}$ & $\begin{array}{l}\text { Semi-fine } \\
\text { turning }\end{array}$ & 0.183 (IT11) & 0 & 1 \\
\hline & 3 & Fine turning & $\begin{array}{c}0.066 \text { (IT8- } \\
9)\end{array}$ & Grinding & 0.046 (IT8) & 1 & 0 \\
\hline & 4 & Fine grinding & 0.030 (IT7) & $\begin{array}{c}\text { Diamond } \\
\text { turning }\end{array}$ & 0.019 (IT6) & 0 & 1 \\
\hline & & & & 0.019 (f6) & & & \\
\hline
\end{tabular}

